\title{
Supply chain mapping initiatives in the Brazilian automotive industry: challenges and opportunities
}

\author{
Dario Ikuo Miyake \\ Escola Politécnica, Universidade de São Paulo \\ dariomiy@usp.br \\ Alvair Silveira Torres Junior \\ Faculdade de Economia, Administração e Ciências Contábeis, Universidade de São Paulo \\ alvair@usp.br \\ Cleber Favaro \\ Faculdade de Engenharia Mecânica, Universidade de Campinas \\ cfavaro@uol.com.br
}

\begin{abstract}
Leading manufacturers that have advanced in the streamlining of internal processes are realising that the accomplishment of further performance gains implies stretching the deployment of process improvement efforts beyond their boundaries. In this context, there is a growing interest in extending mapping activities to inter-plant and inter-firm levels. However, research on the conditions under which such an initiative has actually been tackled in industry is still incipient. Based on multiplecase study method, this paper discusses some supply chain (SC) mapping initiatives undertaken in the Brazilian automotive industry. The study examines the major motivations, difficulties, and outcomes observed in the cases, as well as the methodological approach adopted in their realisation. The cases reveal that despite its intrinsic complexity, the SC mapping process provides invaluable opportunities to strengthen the SC capabilities. However, its adoption as a formal management method with strategic implications will depend on clearer understanding of its relevance and potentials.
\end{abstract}

Keywords: Supply chain; suppliers; process mapping; materials flow; capability

\section{INTRODUCTION}

Process mapping, as an analytical method, has been widely applied as a fundamental technique for systematic problem solving and process analysis by adherents of performance improvement programs such as Total Quality Management and Six Sigma. It is also a basic activity in the deployment of projects like business process reengineering and information system implementation. In firms that are in a more advanced stage of implementation of production and management systems that fulfil world class standards, building process maps by tracing step by step the sequence of operations or the flows of materials, information, or people, nowadays is a commonplace activity, and the resulting maps have become an indispensable managerial document.
As competitiveness at market tends to be determined not only by the capabilities of individual manufacturers, but by the amalgamation of a number of supply chain (SC) members' capabilities, there is a growing concern to broaden the perspective of mapping (Fine 1998, Gardner and Cooper 2003). Advocates of SC mapping hint at that the extension of the mapping process enables the grasping of a clearer view and understanding of the SC members' actual capabilities as well as of the whole chain dynamics. This would facilitate managerial actions such as assessment, redesign, alignment, and integration of the SC, besides environment monitoring for strategy planning and deployment.

According to Jones and Womack (2002), four levels of process analysis can be considered when map- 
ping production flows as follow: (1) process level, (2) single plant, (3) multiple plants (of a same company), and (4) across companies. While the maps built in first two levels provide a rather detailed view of internal process within a single facility, the maps in levels 3 and 4 offer a multiple facilities perspective facilitating the exercise of seeing a bigger part of a whole SC. The minimum scope of extended SC mapping implies observing the flows of materials and information across one or two facilities upstream from the position where the mapper is. The extended perspective of supplier-buyer links is fundamental for tackling issues related to the challenge of SC integration. Harland et al. (1999) suggest that when devising supply strategies, the integration of supply activities can be considered in four levels as follow: (1) within firms, (2) in dyadic relationships, (3) in chains of firms, and (4) in inter-organisational networks.

Discussions on SC mapping cases are found in academic works which brought to light the applicability and potential benefits of such a method (Hines and Rich 1997; Naim et al. 2002; Childerhouse and Towill 2003; Harper 2007) as well as in reports on SC mapping projects carried out by practitioners (Drickhamer, 2006). In general, these SC mapping efforts focused the flow of a specific product family and basically covered two echelons of the SC examined. To date there are few evidences of firms that accomplished to institutionalise the practice of extended mapping activities and learned how to systematically exploit its promising outcomes. To grasp a view of the initiatives actually taken towards SC integration, Fawcett and Magnan (2002) investigated the experience and perspectives of industry managers engaged in SCM and found that SC practice seldom resembles the theoretical ideal. Concerning supply chain visibility, these authors observed that, with the exception of a couple of firms, no firm in the sample surveyed had formally adopted SC mapping activities. Despite the strategic relevance of SC integration, rare managers have actually invested the time and other resources needed to get a clearer picture and holistic understanding of their most important supply SCs.

This hints that the adoption and effective application of this process may entail not trivial managerial issues like commitment to rigorous, fact-based analysis and need to count on special resources (e.g. deeply-experienced 'mappers', more influential project managers). Moreover, the arrangement of SC mapping projects seems to involve a complexity of greater magnitude than the usual exercise of process mapping within the boundaries of one's own firm.

This work explores the conditions under which SC mapping initiatives have actually been tackled in the context of the Brazilian automotive industry. In 2003 Brazil was the tenth world's largest producer of motor vehicles, but in 2009 its production achieved a total of 3.182 million motor vehicles and ascended to world's sixth position (International Organization of Motor Vehicle Manufacturers). This growth has been supported by a diversified local autoparts industry. The Brazilian Association of Autoparts Manufacturers (2007) comprised of 488 member firms that represents roughly $95 \%$ of of the autoparts industry in Brazil, reported that total sales of this sector amounted to US $\$ 29.8$ billion in 2006. Similarly to what occurred in countries where the automotive industry has a longer tradition, the firms of this industry have undergone a shakedown over the past decade in Brazil which involved major investments in the restructuring and modernisation of manufacturing operations, integration into global production networks, and launching waves of new models. In addition to this, factors like the development of the biofuel industries, the introduction of commercially viable vehicles powered by flex-fuel engines, and the achievement of more advanced capabilities by local engineering and development centres provided further impulse. Thus, major players in the Brazilian auto industry - not only motor vehicle manufacturers, but also those in the autoparts supply base - are becoming increasingly aware and responsive to new trends and demands, and have driven efforts to catch up world-class standards.

The effective adoption of SC mapping processes may lead to yet unexploited ways of inter-firms projects and transactions that may enhance the valuechain overall performance. This study presents and analyses three SC mapping initiatives identified in the Brazilian automotive industry considering its methodological aspects and their outcomes, and delineates potential strategies to foster more effective development of its application.

\section{SUPPLY CHAIN MAPPING}

\subsection{The purpose of mapping a supply chain}

Diverse reasons may impel or induce the mapping of a SC. Gardener and Coopers (2003) suggest that while conventional process mapping has typically an internal orientation and tactical purpose, SC mapping has 
a clear external orientation and rather strategic purpose. For these authors, the SC maps produced in SC mapping initiatives enhance consistency in intraand inter-firms communication, can be used to register and distribute key information to support agile management in dynamic environments, and facilely orient new individuals or firms to their role in the SC. Moreover, SC maps can be built with a descriptive or prescriptive purpose, thus offering a basis for SC redesign or modification, and can facilitate the monitoring of SC integration progress.

As for the process of SC mapping in itself, it does not merely facilitate the grasping of a clear perspective and understanding of the current channel dynamics (i.e. in terms of member's relative size, power, competitive positioning, future importance), define the perspective of the SC integration efforts, and promote a common understanding of the SC among its players, but also lead to improved SC management procedures and link corporate strategy to SC strategy.

\subsection{Mapping approach and method}

SC maps can be drawn in a number of shapes and styles considering different analytical perspectives, but in general, are a representation of the linkages and members of a SC along with information about products, flows, processes, or facilities (Gardner and Cooper, 2003). The process of building of SC maps can be organised and carried out in different ways. With the purpose to establish both conceptual and methodological grounds to support SC mapping, different approaches have been formally proposed. Some major alternatives follow below:

- Jones and Womack (2002) advocate the application of the value stream mapping (VSM) method (Rother and Shook 1998) - proposed to trace the existing flows of materials and information from a firm-centric view and then to design a future streamlined state - should be extended to a broader context of analysis, considering multiple plants or multiple firms that are part of a given SC. This derivative method is named extended value stream mapping (EVSM) and, ideally, should cover as much of the entire SC as possible, from raw materials to the final end customer. The application of this method entails joint work of business partners to streamline production and transportation processes in the focal SC.

- Grounded in a contingency approach, Hines and Rich (1997) organised a toolkit comprising seven value stream mapping tools that allows the selection of the most appropriate one(s) for those who wish to identify and then reduce or eliminate wastes in the context of extended value streams. The consideration of which tools to use in what circumstances is based on a simplified version of the value stream analysis tool (VALSAT) proposed by Hines et al. (1998). Case studies developed in the British automotive SC were organised by Taylor and Brunt (2001) to illustrate the application of these tools. In a more recent work, Hines et al. (2000) organised a complementary package of tools to map the information flow and foster the strategic alignment of improvement initiatives throughout the SC.

- Based on the concept that depending on the industry, products, processes and organisation evolve at different rates, Fine (1998) proposed the approach of dynamic clockspeed analysis which entails mapping the SC in three levels, i.e., organisational SC map, technology SC map, and business capability chain map. The power of this mapping approach lies in the possibilities of discovering risks in the chain, what can help in the prevention of potential crises, and of identifying opportunities for improvement.

- Aiming to support the development of seamless supply chains, Towill, Childerhouse and Disney (2000) presented the quick scan methodology (QSM) which is based on the idea of assessing uncertainty in the product delivery process and reducing it by tackling root causes inherent to immediate customers, suppliers, as well as the value added process and control system of the focal firm.

- The Supply Chain Council (2006) developed the Supply Chain Operations Reference-model (SCOR) for representing a SC configuration by capturing the state of five core processes (namely: plan, source, make, deliver, and return) of its constituent firms. This reference model integrates concepts of business process reengineering, benchmarking, and process measurement into a cross-functional framework, and aims at promoting effective communication among SC partners.

- Lambert et al (1998) assert that to capture the full potential of successful supply chain management (SCM), an explicit knowledge and understanding of how the SC is configured should be grasped so as to identify the members with whom it is criti- 
cal to link, what processes need to be linked, and what type/level of integration applies to each process link. To facilitate this they suggest the use of a diagram called supply chain network structure that besides exhibiting the business process links between a focal firm and its suppliers and customers that define the horizontal (number of tiers) and vertical (number of firms in each tier) structures of the considered SC, also characterises the kind of the mapped links (e.g. a process link may be actively managed or just monitored or not-managed for not being critical enough).

A SC map result from the collection of different kinds of data (e.g. demand, customer-supplier links, capacity, inventories, travel distances, lead times) and provides a holistic view that no one person has ever caught in its entirety. The mode of organising and exhibiting the information gathered in a SC mapping exercise varies depending on the method adopted. In most plain forms, a SC map may resemble a tree diagram or a network graph in which a node represents a function, division, plant, firm or even an industry depending on the level of aggregation, and the links represent the supply relations among them. A similar mode is the exhibition in a form that resembles a high level block diagram or process map in which the building blocks contain specific processes, macroprocesses, facilities, or firms. Depending on the form of SC map, different types of flow are considered: (a) customer orders or sales forecasts transmitted upstream the $\mathrm{SC}$, (b) materials flowing downstream from raw materials to customer, (c) return channels and feedback loops. For a more sophisticated form of visual display, SC maps can be based on richer graphic conventions that consider a set of pictorial icons instead of nodes or blocks, and a set of line styles to specify the nature of functional links or flows between the mapped entities. The maps obtained from VSM and EVSM methods are typical examples of this form. Alternatively, SC maps can be drawn on geographic maps to provide spatial visualisation.

\section{RESEARCH METHOD}

The purpose of this work is to develop a better understanding of the SC mapping process by investigating some application initiatives identified in the Brazilian industry. The study has a focus on the automotive industry, where shop floor streamlining actions grounded on operational excellence-oriented production principles and tools are now being deployed in numerous plants, and an increasing awareness that further improvements can be sought in SCM capabilities has been observed. This concern is especially noticeable, in those firms that have already accomplished significant progress in the rationalisation of business processes within their own domains. Such leading firms have, typically, promoted, organised, and rolled out their operations improvement efforts based on managerial models like lean production, total productive maintenance, six sigma, and theory of constraints. The deployment of such actions in itself involves a constructive organisational learning process and this has nurtured the development of a more systemic view of the overall value chain in which the firm is embedded.

This work intends to inquiry why such leading firms that are exemplary adherents of operational excellence programs - with a particular emphasis on lean production - and promoters of SCM best practices would embark on a SC mapping project and how such a project has been deployed. Given that these types of inquiries entail the grasping of the sequentiality of the happenings, the focus is on a contemporary phenomenon within its real-life context, and the main interest is in covering broadly defined research topics (not a limited number of specific variables) the case study research strategy was adopted (Yin, 1994).

The sample studied is comprised of three cases that were selected using replication logic and considering the following criteria for inclusion:

- The case refer to a typical firm that undertook a relevant initiative of exploring the potential of the SC mapping in the above mentioned context.

- The decision to deploy the SC mapping project arose from the discretion of key managers that a specific SC mapping approach they had gotten acquainted with, could be instrumental in coping with critical issues they faced in their supply base; rather than persuaded by external actors or forces.

- Since the automotive industry can be segmented into a variety of business sectors, the cases should refer to firms established in different sectors.

The selected cases refer to firms that offered sufficient access for the development of in-depth investigations and are established in different sectors of the automotive industry as follow:

- an assembler of commercial vehicles (CVA);

- a carmaker (PCA); and

- an automotive systems supplier (APS). 
The sample illustrates pioneer projects in which practitioners strived to exploit an emerging methodology when there were still few evidences of their actual benefits and efficacy. Firm names are not identified at the request of the focal firm considered in the cases specially for involving commercial issues concerning their sourcing policies (e.g. competitive quotations, supplier assessment and selection, second source development, contractual terms for technical changes in product/process). Based on multiple case design, the SC mapping initiative driven by are longitudinally investigated.

It is worth mentioning that from among the six methodological alternatives focused in the previous section, at least two got greater visibility in Brazil: the work of Fine (1998) on dynamic clockspeed analysis, and the work of Jones and Womack (2002) on EVSM. Local editions of these works were even published in Portuguese in 1999 and 2004, respectively. As will be described in the case studies, the kick-off of the focused SC mapping experiences occurred between 2003 and 2004.

The cases presented are either a real project in which one of the authors of this paper played a major role in the team assigned to conduct the SC mapping initiative, or a project which was closely followed up by one of the authors throughout its development. In the former situation, one of the authors participated in the team that deployed the focused SC mapping project either as a senior engineer of the OEM organisation or as an external consultant hired to support process improvement projects; and thus both direct and indirect observation methods could be applied (Stake 2005). In the second situation, a middle rank manager of the OEM organisation that had the responsibility to coordinate the focused SC mapping project agreed to cooperate in the elaboration of an academic study about this experience so that one of the authors could follow its realisation gathering data through indirect observation. In all cases, the mapper agent participated in the team that tackled the data gathering activities as well as in the subsequent stages of data analysis and development of action plans involving the focal firm and respective suppliers. For the confirmation of the general outcomes reported by the mapper agent, the first author interviewed other two or three senior level informants who work in functions like Manufacturing, Quality, and Production Planning in each focal firm. A methodological limitation is that no one from the mapped suppliers could also be interviewed to consider a two-way perspective.

The underlying motivation of this work was to explore the conditions under which actual SC mapping initiatives have actually been tackled by developing a descriptive study. The investigation of the three case studies was directed by, specific research issues concerning the considered SC mapping initiative as follow:

- What were the motivations and objectives that led the SC mapping initiative?

- Which mapping approach/methodology was taken by the focal firm in the case?

- What difficulties were experienced by the firms involved in the SC mapping project?

- What were the outcomes accomplished by the SC mapping initiative in the short-term?

- What were the subsequent developments from the early SC mapping initiative?

\section{The launching of the initiative}

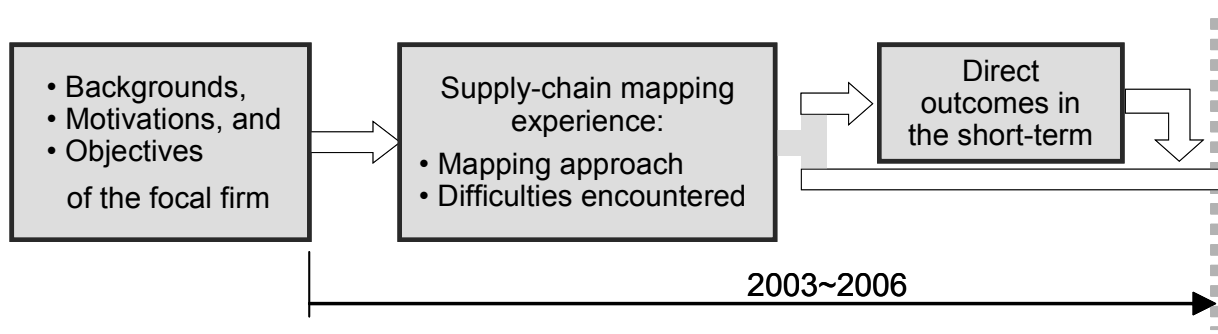

\section{The outcomes of the early supply- chain mapping initiative}

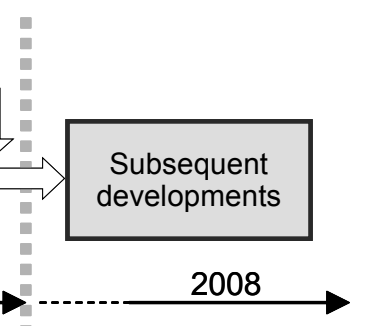

Figure 1. Structure of each case study 
Figure 1 exhibits the framework considered in the development of the case studies making use of the chronological structure (Yin 1994). It comprises three elements that contemplate the above mentioned research issues. The first element addresses the launching of the SC mapping initiative and includes the motivations and objectives of the focal firms. The next element focuses on the carrying out the early SC mapping projects which, to a great extent, were undertaken in the period between 2003 and 2006. It comprises the characterisation of the mapping approach/methodology applied by the focal firm, and of the difficulties which were experienced. This is followed by the consideration of the main outcomes of the early SC mapping initiative which are divided into direct outcomes accomplished in the short-term and subsequent developments. The data gathering for the development of the cases studies was divided in two stages. Those related to the first two elements and direct outcomes were obtained before 2007. Later on, each case was completed with a follow-up investigation carried out in April 2008 to examine subsequent developments from the considered projects.

\section{THE CASES IN BRAZILIAN AUTOMOTIVE IN- DUSTRY}

In this section, the cases are presented accordingly to the descriptive elements structured in Figure 1.

\subsection{Case CVA}

\section{Backgrounds and motivations}

CVA is a plant of a global player that produces commercial vehicles, which since 1995 has undertaken great efforts to improve its operational performance grounded on the lean production system. The kickoff of this journey was compelled by the policy of economic liberalism established by the Brazilian government in the mid-1990s that induced a significant increase in market competition, and by the fact that the traditional bureaucracy that prevailed in the firm was inept to promote the organisational changes required to restore the firm's competitiveness. Thus, the board decided to revamp the manufacturing facilities of CVA by promoting the implementation of the lean production approach. This change process can be divided into two phases.

In the initial phase, from 1995 to 2002, the Brazilian board was given autonomy to plan and deploy a strategy to recover CVA's profitability. Then they hired a very experienced consultant - a former manager from Toyota - of an international consultancy firm, who started a Kaizen program at CVA to replace the mass production paradigm embedded in the management's bureaucratic mindset by the principles of lean production system. During this phase, major causes of wastes were identified and reduced/eliminated through the realisation of approximately 3,500 kaizen workshops. In the beginning, these workshops were confined to Production, but since the ultimate objective was the transformation of CVA into a lean enterprise, gradually other areas like Maintenance, Production Planning, Quality, Engineering, and Finance were also involved. As a result of this, the dissemination of lean thinking triggered a profound paradigm shift in the firm. The success accomplished in this effort was acknowledged group-wide and the plant received many visits of managers from other business units around the world.

The second phase started in 2003under new directives set by the board: the change process and diffusion of the lean production model would continue, though without the support of external consultants. This allowed team leaders of improvement projects to exploit tools and proposals that had not been endorsed by the consultants. In the same year, middle managers of CVA launched an initiative to foster the dissemination of lean production concepts and practices in first-tier suppliers.

\section{The CVA supply chain mapping initiative}

One of the projects deployed with this goal was the establishment of a process to support the development of suppliers' capabilities grounded on the EVSM approach (Jones and Womack, 2002), whose adoption had not been prescribed by the ex-Toyota consultant. While technical experts of the Toyota's supplier development programs carry out thorough on-site assessments at suppliers' plants and even provide assistance to improve their managerial capabilities, they do not put emphasis on a formal mapping method like EVSM (Sako, 2004). The experience of applying EVSM was preceded by preliminary contacts with some suppliers and by the participation of some managers in a major training event. Following this, one manager decided to promote the application of this approach in his area. The primary motive to devise such an initiative was to promote the lean principles in some suppliers and to provide support to improve their production flows and product quality. However, the proposal of working together with suppliers was perceived by the Purchasing depart- 
ment as a form of interference in commercial deals, and eventually it was only authorised by the board on the condition that its main objective were restricted to achieving cost reductions. The proponents of this experience abode by this directive and then put it into action their plan.

In March 2003, a supplier that produced one of the most expensive components of CVA vehicles was selected to be the counterpart of the first experience. This firm is located about $200 \mathrm{~km}$ of distance and its major manufacturing capability relies on the foundry process which enabled it to become a major supplier of cast-iron parts. The managers of this supplier were reluctant to participate in the proposed program as they had doubts about the benefits it could bring. The main reason was the fact that in the relationship between CVA and its SC members, traditionally, the former exerted its bargaining power to take advantages to the detriment of the latter ones. Thus, to get the agreement of this supplier's managers, the CVA team emphasised the existence of great opportunities for process improvements by the removal of wastes at this supplier's plant and offered a deal to share the gains this program might render. This deal was then further discussed and finally established between both parties.

To conduct this program, a multifunctional task force constituted by members from both firms was set up. Each firm assigned a group of 6 to 8 persons to this task force representing areas such as process engineering, product development, maintenance, production, quality control, and logistics. At first, both groups received a one-day training session in the VSM method. Next, in another full day, the task force visited the CVA plant and tracked along the flow of the focal part produced by this supplier to map its value stream. After that, another one-day mapping session was carried out in the supplier site to complete the mapping and build an integrated perspective. Then, the groups analysed together the maps of both parties exhibited in Figure 2 and identified opportunities for improvement.

Each opportunity identified by this EVSM motivated the realisation of kaizen workshops. An agenda of kaizen weeks with specific purposes was established to improve elements like process capability, component design, standard work, quality assurance, and production facilities. Although in the essence of lean thinking, cost reduction is rather considered a consequence of improvement actions, in this case, both firms had expenditures with transportation of the team and time devoted to the project, thus there was a keen understanding that cost reduction targets should be met. To remove the distrust on the criteria to capture the savings this project would accomplish, it was necessary to reinforce that they would be shared between the two parties after the end of kaizen weeks.

\section{Short-term outcomes}

Along the project, two kaizen weeks were carried out at each firm, focusing five critical areas identified in the EVSM as follow:

- Creation of a finishing cell in the supplier's plant to replace a traditional line with transfer of cell design and cell implementation know-how from CVA to supplier;

- Change of some features of a mould part produced by the supplier to reduce difficulties caused to CVA's manufacturing process. The supplier did not know the problem caused to CVA, but could rapidly implement an easy solution without investment. CVA engineers had already thought of this solution, but did not request it supposing it would be too costly to supplier;

- Elimination of a painting operation at the supplier, which was executed based on the assumption that it was important to the counterpart. In reality, it was not necessary any more on account of changes implemented over the time, but none of the parties had realised it should have been interrupted;

- Addition of a new characteristic in the mould part to facilitate a set-up operation at CVA plant. The CVA engineers would not ask the supplier to implement it supposing that this would entail a major modification in the mould, but the supplier found an easy way to tackle it;

- Transferring of an operation from CVA plant to supplier as it was more adequate to be done in an earlier stage.

To a great extent, the improvements were accomplished just by the integration of the assigned team, exchange of information, and knowledge sharing. As a result of the kaizen weeks the lead-time was shortened from 102.5 hours to 53.6 hours in the supplier and from 46.5 hours to 42.5 hours at CVA. As Figure 3 indicates, it was also found that lead-time could be further shortened to 28.6 hours at CVA. Be- 
sides these, the scrap rate was reduced from $8 \%$ to $2 \%$, a job position was cut in the supplier, and with the cost reduction achieved the mould part price could be reduced about $15 \%$. After the success of this experience, this promising approach was repeated in more suppliers with similar results. Among the intangible benefits brought by this initiative, CVA highlights the opening of constructive channels to discuss problems involving the technical departments in the suppliers, overcoming traditional interface conflicts.

\section{Subsequent developments}

After this initial experience, this type of intervention was repeated in more direct suppliers. However, after 2004, the nature of top management's support to the deployment of lean production approach changed significantly, and the sponsor of the program was successively replaced. As of early 2008, the leader of the program was not any more a key member of top management and the steering office that once supported the roll-out efforts had been dismantled.
Nowadays, CVA managers are rather striving to foster compliance with the requirements of the corporate production system reference model framed by the global headquarter. In the conception of this model, VSM is not regarded as a higher level approach, and is listed as just an item among a set of 69 tools whose application is verified in periodic audits. Thus, at the group level, all plants worldwide have been compelled to implement lean production in a more standardised way. Despite the far reaching impacts of this policy, the implementation process continued in a rather bureaucratic way and much confined to the production function. The trajectory of effective promotion of the lean paradigm was interrupted and the bureaucratic behaviour regained momentum due to the headquarters' understanding that the lean system is a set of management tools. Inappropriately, VSM became a typical convenience tool to show compliance with the reference system. As for the EVSM, since it was not included among the 69 tools, managers have little interest in its application. When a SC mapping project is required, the scope of the EVSM application is limited to the involvement of a single $1^{\text {st }}$ tier supplier.
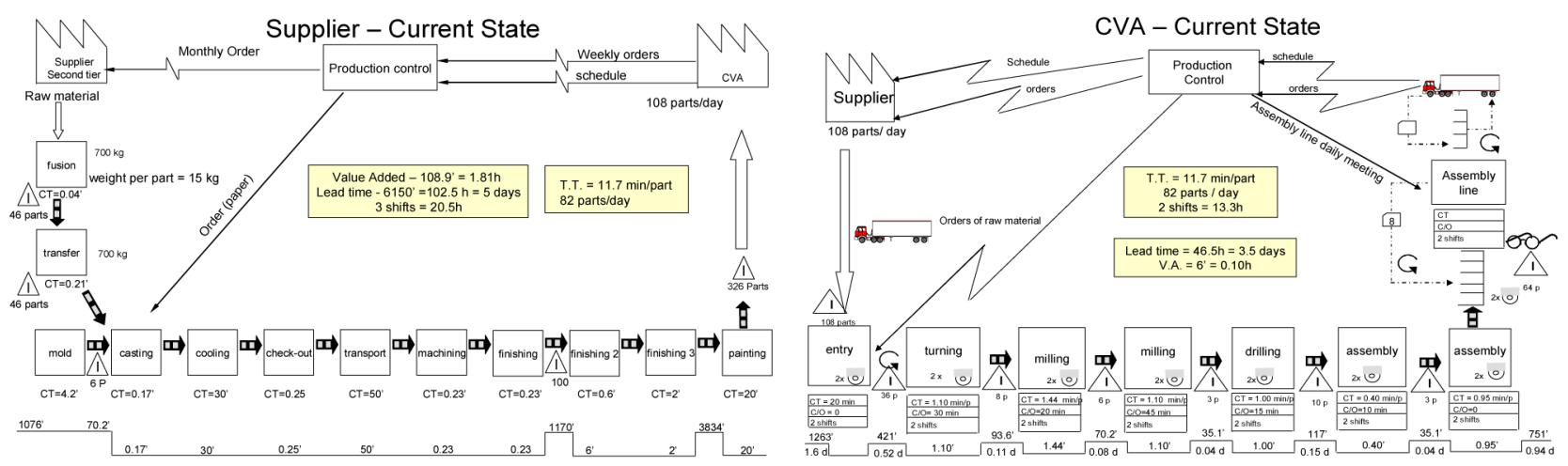

Figure 2. Current state map of a value stream in the plants of a supplier and CVA
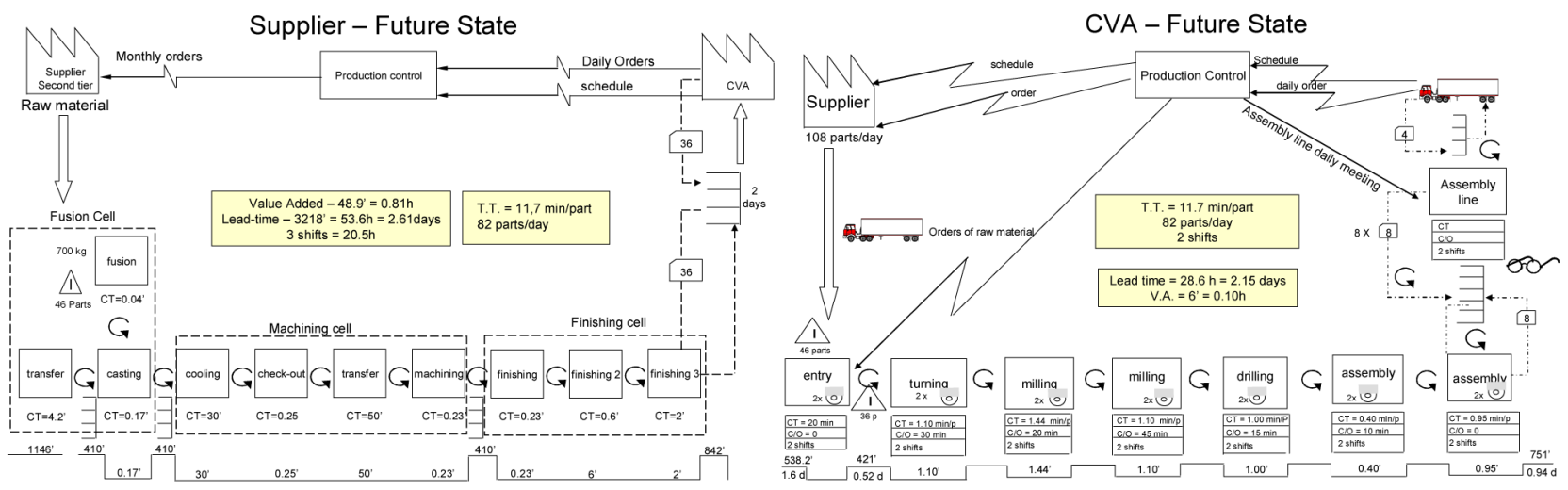

Figure 3. Future state map of a value stream in the plants of a supplier and CVA 


\subsection{Case PCA}

\section{Backgrounds and motivations}

PCA, the firm focused in this case, is the main plant established in Brazil by a global leader in the market of passenger cars. In 2004, PCA faced the challenge to devise a plan to step up its production capacity so as to cope with the trend of rapidly increasing demand. A major concern was to ensure proper parts delivery in terms of volume and product mix. A total of about 16,000 types of parts are supplied by the PCA's SC base. Given the constraints to consider the supply of every part, the Purchasing department decided to concentrate on the investigation of the suppliers responsible for most strategic parts to verify their actual production capacity. This case is related to the mapping of the SC responsible for the supply of manual transmissions. PCA decided to initially focus on this chain motivated by the fact that it was already operating close to its maximum capacity and, previously, had even caused severe supply disruptions to PCA's assembly lines. This called for urgent strategic countermeasures as transmissions are high valueadded parts that constitute one of the most critical vehicle systems, and their production can not be easily undertaken by alternative suppliers.

\section{The PCA supply chain mapping initiative}

The realisation of the extended mapping of this chain was carried out from March 2004 to July 2004 involving a team coordinated by a PCA's manager and key members of involved suppliers (Roldan 2005). The mapping procedure applied was based on the approach presented by Fine (1998), contemplating the mapping from the organisational and business capability perspectives. For the specific purpose of this project, the mapping concerning the technological perspective was not applied. The organisational mapping was not restricted to the investigation of the $1^{\text {st }}$ tier supplier (S1) since the causes of delivery failures were not confined only in this firm. Based on a preliminary general assessment, the mapping was extended to other three $2^{\text {nd }}$ tier suppliers (S1.1, S1.2, S1.3), and since among these, S1.3 inspired greater concern, three $3^{\text {rd }}$ tier suppliers linked to it (S1.3.1, S1.3.2, S1.3.3) were also included in the project scope. Figure 4 exhibits the hierarchic supply relations considered in the set of 7 suppliers that constituted the critical part of this focal SC.

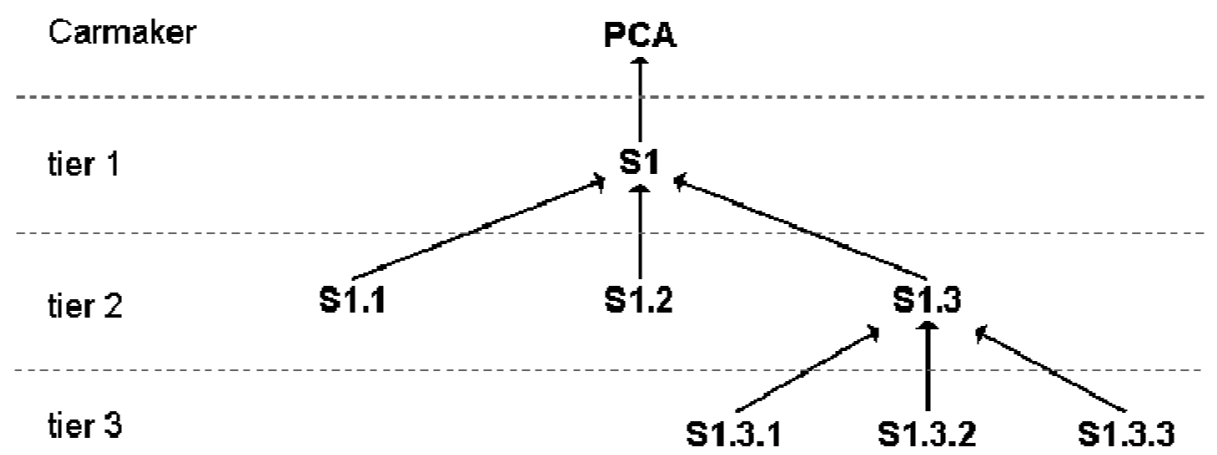

Figure 4. Focal firms comprising PCA's supply chain for transmissions.

The analysis of their capabilities focused the production capacity to fulfil PCA's orders in terms of volume and product mix. To assess the supplier's potential capacity, the extended mapping considered the actually installed capacity, instead of the planned capacity share set aside by the suppliers for the production of the transmissions ordered by PCA, based on long-term capacity reservation contracts. A premise of this was that PCA would have to renegotiate the terms of these agreements if additional capacity were required.

The information raised through the extended mapping of this focal SC revealed that only one firm
(S1.2) among the seven considered was not affected by capacity constraints to fulfil the increase in order quantity and the changes in product mix required by PCA. On the other hand, a series of action plans had to be devised and established for each of the other six firms to cope with their specific capacity issues aiming at the accomplishment of the required increase in the capacity of the entire SC.

\section{Short-term outcomes}

Among the primary action plans derived from this project, one concerned PCA itself who acknowledged the need to decline new sales opportuni- 
ties in case transmission requirements exceeded the increased production capacity of this SC. Also, PCA agreed with S1 to promote the sales of cars equipped with automatic transmissions to conciliate available production capacity with demand, and endorsed S1 in the decision to decline the exports of parts to other plants of the group PCA belonged to for a certain period.

Table 1 synthesises the main action plans devised to assure proper delivery of parts in this critical chain, in the short and medium terms. It is worth noting that this extended mapping unveiled that in two suppliers (S1.1, S1.3.1), the already high utilisation rates of the required resources would not enable them to cope with the production volume rise expected by PCA. In devising possible action plans to deal with these bottlenecks, it was realised that these suppliers had financial constraints to invest in additional capacity for fulfilling larger orders. Thus, the action plans addressing them included commitment of capital investments by PCA to support their capacity expansion needs.

Table 1. SC firms mapped by PCA.

\begin{tabular}{|c|c|c|c|}
\hline Supplier & Item & No. of SKUs & Action plans \\
\hline S1 & Transmissions & 23 & $\begin{array}{l}\text { "Urgent imports of transmissions by air freights } \\
\text { " Imports of internal subsystems to alleviate demands to local } \\
\text { suppliers } \\
\text { » Development of a second local supplier for items supplied by } \\
\text { S1.3 }\end{array}$ \\
\hline S1.1 & Differential systems & 14 & $\begin{array}{l}\text { „ Extend the working time of production shifts } \\
\text { » Participation of PCA in joint investments to raise production } \\
\text { capacity }\end{array}$ \\
\hline S1.2 & Transmission cases & 4 & »No action required \\
\hline S1.3 & Gears sets & 74 & $\begin{array}{l}\text { Extend the working time of production shifts } \\
\text { " Additional production shifts in weekends } \\
\text { "Streamline production flow to rise productivity } \\
\text { " Plan inventory building in periods of lower demand } \\
\text { " Revert production of a part that had been outsourced to } \\
\text { S1.3.2 to alleviate its capacity utilisation } \\
\text { "Development of a second local supplier for items supplied by } \\
\text { S1.3.2 }\end{array}$ \\
\hline S1.3.1 & Gears & 8 & $\begin{array}{l}\text { "Urgent imports by air freights } \\
\text { » Participation of PCA in joint investments to raise production } \\
\text { capacity }\end{array}$ \\
\hline S1.3.2 & Forged parts & 12 & $\begin{array}{l}\text { » Contract of external production capacity } \\
\text { » Replace the use of two different parts with similar functions } \\
\text { by one (commonisation) to eliminate setup losses }\end{array}$ \\
\hline S1.3.3 & Assembly cubes & 6 & $\begin{array}{l}\text { » Imports from an alternative supplier } \\
\text { »Development of a second source of materials }\end{array}$ \\
\hline
\end{tabular}

This SC mapping project was motivated by the need to cope with delivery shortcomings in a rather reactive way. But still, it provided a systemic understanding of a very critical situation and enabled PCA to assure proper transmission delivery in the shortterm. Moreover, it made possible the anticipation of even worse problems and delineation of action plans that would assure the fulfilment of its transmission requirements in the medium-term (over a period of about one year). The participants of this extended mapping effort could realise that if this approach was applied proactively to assess SC conditions, it would render even greater benefits such as identification of waste elimination opportunities, improvements in SCM practices, and alignment of SC members' capacity planning to PCA's production plans in terms volume and product mix. 


\section{Subsequent developments}

In spite of the valuable insights that this experience brought about, and the potential of incorporating the planning and analysis rationale of the SC mapping based on Fine's (1998) approach as a managerial tool at PCA, the lessons learnt in this initiative were rather confined as tacit knowledge of the team that tackled the project. The fact that after this project, the VSM and EVSM methods were formally included by the global headquarter into the corporate managerial toolkit as reference methods for SC mapping, hindered further development and dissemination of the preceding approach at PCA.

Likewise in the case of CVA, over recent years, PCA has been compelled to reorganise the plant to comply with the principles of operational excellence advocated by the corporate production system which is currently being globally deployed throughout the group PCA belongs to (Miyake and Nakano 2007). But since in the case of PCA the assessment of the production system emphasises the adherence to principles, specific tools like VSM have been applied rather parsimoniously.

As of early 2008, in the structure of PCA, the Supplier Assessment team was the organisation unit that was most closely related to the concept of SC mapping. This team is comprised of 9 experts that are requested by buyers and controllers whenever a supplier requests price increases. Thus the role of these experts is to tackle cost breakdown analyses gathering data through supplier assessment methods and verify how fair is the request to, eventually, subsidise renegotiation deals. In April 2008 only two experts were well versed in value stream analysis and could apply VSM in suppliers' site. The manager of this team wished more experts were acquainted with VSM, but he realises that few people are actually prepared to apply them skilfully and get accurate data. As for application of EVSM at interfirm level, it remains sub-utilised.

\subsection{Automotive Parts Supplier (APS)}

\section{Backgrounds and motivations}

This case is considered in the context of supplier development efforts undertaken by APS, a division of a major auto-parts supplier in Brazil that belongs to a group ranked among the largest in the global automotive business (Favaro and Lima, 2005). APS is a first tier supplier of automotive systems with an- nual sales revenue of about US\$750,000,000. About $70 \%$ of its production is exported to customers in the United States and Europe, and the remainder is supplied to local automakers. It operates a plant with a workforce of about 4,000 employees that produces 7 different product families requiring the purchasing of some 3,000 types of parts from a supply base constituted by about 80 local suppliers. Over a period of 5 years, the APS's Purchasing department deployed a strategy to reduce the number of suppliers, and in 2006 its 7 main suppliers already represented 90\% of the financial volume of locally purchased parts and $87 \%$ of the inventory held. In late 1990 s, the APS plant pioneered the implementation of lean production system within the group in a worldwide context. However, until 2004 this effort was restricted to stand-alone application of specific tools and practices fostered by advocates of lean production.

\section{The APS supply chain mapping initiative}

In 2004, the deployment of lean production system was restarted based on a more holistic approach and focused on the value stream of 3 product families. For these product families, the material flow consists of the following process steps: soft machining, heat treatment, hard machining, and final assembly. In 2004, APS faced a strong demand growth, specially, in export markets, and this required a quick response to increasing customer orders. The transformation of operations from the traditional mass production to lean production system advanced quite fast at APS plant. However, after achieving significant progress in internal streamlining efforts, APS realised that its suppliers became a constraint and were hindering any further improvements in productivity and delivery performance in terms of quantity, quality, and time.

To overcome this obstacle, the APS Logistics department decided to establish a program to support suppliers in the adoption of lean concepts and techniques. A group with 2 experts in lean production was assigned to this program and its focus was concentrated on achieving cost reductions and $100 \%$ on time delivery. It was also expected to achieve reductions in lost sales and air freights costs. In spite of being aware of the lean supplier development program conducted by the Logistics department, the Purchasing department did not participate directly in this initiative. The program focused on the seven major local suppliers, whose characteristics are summarised in Table 2. 
Table 2. Direct suppliers of APS involved.

\begin{tabular}{cccc}
\hline Supplier & Distance & Main process & No. of purchased parts families \\
\hline SA & $<10 \mathrm{~km}$ & Machining & 70 \\
SB & $<10 \mathrm{~km}$ & Machining & 4 \\
SC & $\sim 20 \mathrm{~km}$ & Surface treatment & 1 \\
SD & $\sim 120 \mathrm{~km}$ & Foundry & 4 \\
SE & $\sim 450 \mathrm{~km}$ & Machining & 21 \\
SF & $\sim 550 \mathrm{~km}$ & Machining & 54 \\
SG & $\sim 1,100 \mathrm{~km}$ & Forging & 3 \\
\hline
\end{tabular}

In general, the firms comprised in the APS supply base are in the stage of seeking competitive advantage through quality control characterised by Hines (1994). Those suppliers featured the following common characteristics: high technical competence, good performance on quality, poor logistics planning system, lack of production management knowledge, absence of a culture of prevention, and skilled in fire fighting. To support these suppliers in streamlining their production flows and in evolving to a more advanced stage of close cooperation, the APS lean experts decided to focus on 1 to 4 parts families of each supplier, considering their impact on the automakers, the state of the value stream they followed in the APS plant, and the financial volume amounted.

To analyse and improve the production flow of each part family in all these seven suppliers, a common approach was applied based on Jones and Womack (2002). The first step was to conduct an initial training on lean manufacturing and VSM. One lean expert sent by the APS Logistics department ran the training sessions and the on site VSM with key people from the supplier. The supplier team included the production supervisor, a quality engineer, and a logistics analyst, and was responsible for producing the current state map and a future state map. Figure 5 illustrates the state of the extended value stream through one of the suppliers and APS when the streamlining project started. After drawing these maps, the team also had to develop process capacity analyses in order to calculate the lot sizes and supermarket sizes at the supplier for the considered product families.

Before starting the implementation of improvements towards the future state, all involved operators were also trained in a practical simulation game that illustrated the principles of flow production and pull system. In addition to this, the suppliers' employees were invited to visit the APS plant and take part in a plant tour to observe lean principles in action. In the case of suppliers SA and SB located close to APS plant, both administrative and shop-floor employees could participate in such events.

The two major barriers to implement the approach were the increasing demand itself that overloaded the suppliers' resources and also the suppliers' mistrust of APS owing to previous similar experiences that had cost reduction as the primary target. Typically, a flow streamlining project took from four to six months to be implemented, starting from the initial VSM event, as long as initial resistance or scepticism was overcome.

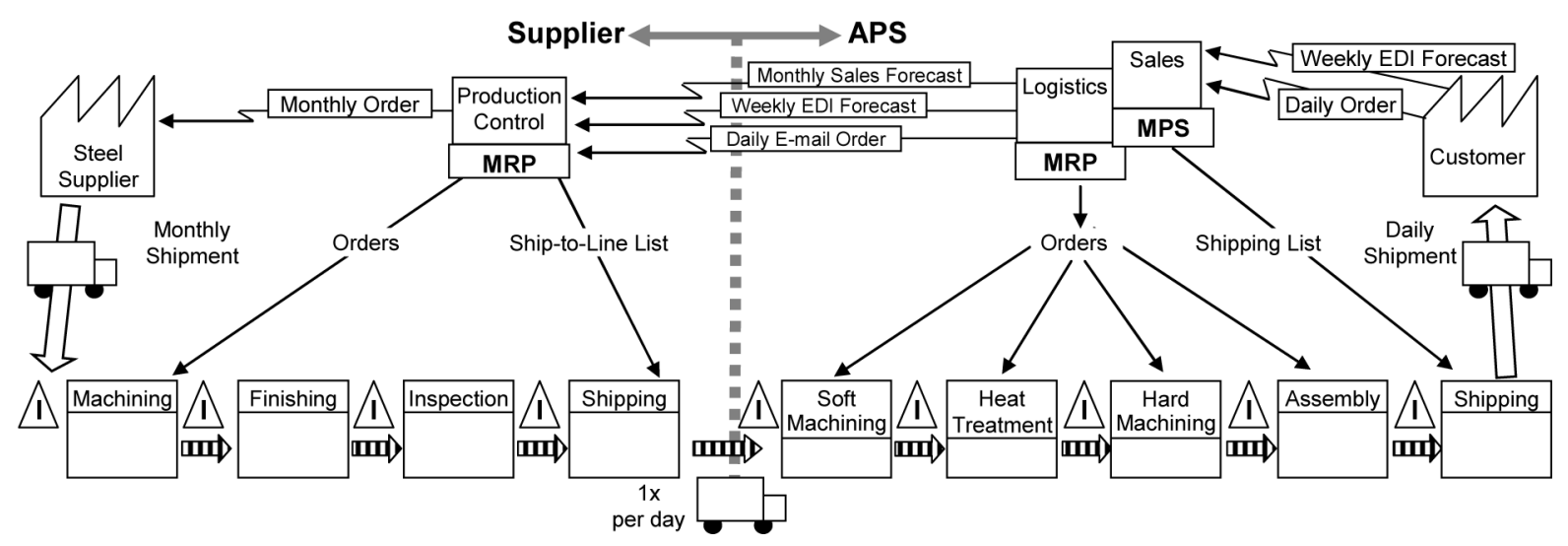

Figure 5. Initial state map of extended value stream (as of early 2004). 


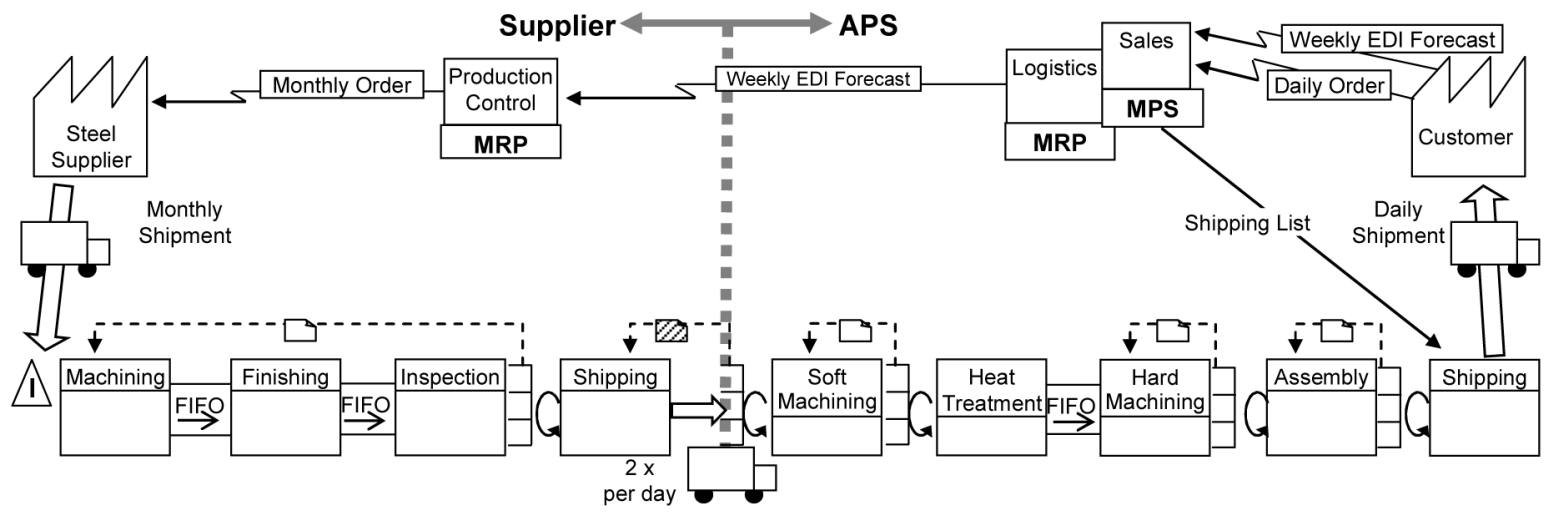

Figure 6. Improved state map of extended value stream (as of early 2005).

\section{Short-term outcomes}

Figure 6 exhibits the value stream that resulted from the rationalisation of the process flow mapped in Figure 5 through implementation of improvements such as internal and external pull systems which enabled significant inventory reductions. The main benefit expected by APS in this supplier development program was the improvement of the inbound logistics processes. This could be achieved for the main parts families of the suppliers involved in the program, in general the following results were obtained:

- Lead times were significantly shortened at APS plant and suppliers as exhibited in the examples of Table 3;

- Enhanced stability enabled to raise on-time delivery (OTD) performance close to $100 \%$;

- Reworking in daily delivery scheduling cut to zero owing to the adoption of a self-managed pull system.

Table 3. Examples of improvements in selected value streams of APS case.

\begin{tabular}{ccccccc}
\hline \multirow{2}{*}{ Value stream } & \multicolumn{2}{c}{$\begin{array}{c}\text { Initial state } \\
\text { (as of 2004) }\end{array}$} & $\begin{array}{c}\text { After improvement } \\
\text { (as of 2005) }\end{array}$ & $\begin{array}{c}\text { Lead time (LT) } \\
\text { reduction }\end{array}$ \\
\cline { 2 - 7 } & OTD & LT & OTD & LT & supplier & APS \\
Supplier SA $\rightarrow$ APS & $85 \%$ & $7+35=42$ days & $99.5 \%$ & $4+20=24$ days & $-43 \%$ & $-43 \%$ \\
Supplier SF $\rightarrow$ APS & $79 \%$ & $9+13=22$ days & $98.0 \%$ & $5+8=13$ days & $-44 \%$ & $-38 \%$ \\
\hline
\end{tabular}

In addition, APS could capture productivity gains of more than $20 \%$. The suppliers participated as partners in these projects and, eventually, were granted part of the resulting cost reductions.

\section{Subsequent developments}

A remarkable lesson learnt by both APS experts and suppliers' team members throughout this program, was the relevance of exchanging information related to the focal parts families from an extended value stream perspective. Simply walking alongside the corresponding material and information flows, allowed the APS and suppliers' teams to quickly identify and eliminate wastes. With the accomplishment of such encouraging results, APS has further intensified the promotion of this collaborative approach and this experience inspired the Latin American corporate headquarter to establish a dedicated team for expanding this program towards the suppliers of other 4 plants in the region and, as of early 2008 , this team comprised 10 experts.

However, although the EVSM had been taken as the flagship method of this program in the beginning, from 2006 on the supplier development team changed their intervention approach to the simpler application of dock-to-dock VSM only at suppliers' plants. Hence, currently, this team spends most of its time out of APS in the suppliers' plants to facilitate the mapping of their internal value streams, identification of wastes, 
and implementation of lean production techniques in order to further improve the overall performance of the APS inbound logistics system.

\section{ANALYSING THE INITIATIVES OF SUPPLY CHAIN MAPPING}

The examination of the case studies considered in the previous section reveals that in all cases, the firms which undertook the SC mapping initiative were large organisations that, previously, had achieved significant progress in developing organisational competences for internal process streamlining. The evolutionary path of these firms indicates that this experience was helpful for understanding the need to build a broader view of relevant suppliers' actual conditions and thus cope with systemic issues that affected their own performance.

The major motivations to tackle extended mapping projects in these cases have been to assure proper delivery (especially in a scenario of rising demand) and to nurture the development of superior production capabilities at relevant suppliers. In the cases of CVA and APS, experts in process streamlining took an important role in the team assigned to the mapping project since the identification of improvement opportunities (e.g. waste elimination) in the suppliers' plants was a major goal for these firms.

From a methodological perspective, the completion of a SC mapping study can be time consuming, and depending on its scope it may demand several months. In the focused pioneering cases of SC mapping projects, different mapping methods were applied depending on the purpose taken into account: in the cases of CVA and APS the EVSM (Womack and Jones 2002) was adopted, while in the case of PCA the mapping was based on Fine's approach (1998). As for the SC perspective, in the former two cases the mapping process involved only a $1^{\text {st }}$ tier supplier while in the case of PCA, the study also included firms located in the $2^{\text {nd }}$ and $3^{\text {rd }}$ tiers. A remark is that the latter case focused on the supply of an autopart that entails a much complex assembly.

The literature on SC management has shown increasing awareness on the potentials of replacing transactions between buyers and sellers that rely on arms-length agreements, based on market price, by relationships that rely more on trust derived from collaboration and information sharing (Hines and Rich 1998; Hoyt and Huq 2000). However, getting the very participation of relevant suppliers in ex- tended mapping projects seems to be a major challenge. In fact, the teams of CVA and APS reported great difficulties in overcoming the mistrust caused by past experiences in which suppliers were ordinarily compelled to meet with cost down demands. Constructive measures like nurturing the development of organisational competences, sharing the accomplished cost savings, and joint investments in capacity increase projects (risk reduction), were considered by the focal firms that undertook the extended mapping initiative, suggesting the importance of adopting a more collaborative standing.

The experts assigned to the mapping process and to the following planning and analyses for searching potential solutions, evaluated that the extended SC mapping is a powerful means that besides fostering improvements to enhance the delivery performance of the involved suppliers, bring about intangible benefits such as:

- improved visibility of the SC actual conditions,

- fostering mutual trust and true partnership among SC partners, and

- unveiling of facts, opportunities and threats with serious implications to the SC performance or reliability, by simply opening and promoting richer communication and cooperation channels between members positioned in a same chain.

These views endorse the idea that SC mapping can effectively support supply-chain development mechanisms that may range from the diagnosis of the SC wastes (Hines et al., 1998), to the articulation of inter-firm learning in the context of a SC (Bessant et al., 2003), integration of selected business process across inter-firm boundaries (Lambert and Cooper, 2000), and exploitation of value stream management drivers to seek the realisation of the lean logistics (Jones, Hines and Rich, 1997).

Notwithstanding these favourable perceptions on the potentials of SC mapping, after the initial deployment of this approach, in all cases, the organisation of the focal firm seems to have been unable to further develop qualitatively its application pattern and incorporate it in operational business process. As a matter of fact, contemplating the practice of the SC mapping in these organisations in early 2008, the process was limited to the analysis of single supplier-customer dyadic relationships. This suggests that the focal firms are still devising a supply strategy that is predominantly in the level 2 characterised by Harland et al. (1999). Moreover, 
the simpler application of VSM in a direct suppliers' plant by PCA and APS implies that, according to the classification of Jones and Womack (2002), they remain practicing process analysis in the level 2 of a single plant without the perspective of the value stream across multiple facilities that enable the building of SC maps. These facts indicate that in their current SC mapping practice, actually they are not seeing much of a whole value stream yet. In the case of CVA, whilst the EVSM method is sometimes applied, when this is induced by a mannerism to comply with the corporate requisites, the very appropriateness or necessity of its realisation can be questioned.

Table 4. Main aspects of the three case studies on SC mapping initiatives.

\begin{tabular}{|c|c|c|c|c|}
\hline Case & $\begin{array}{c}\text { Focal firm } \\
\text { Product segment }\end{array}$ & $\begin{array}{c}\text { CVA } \\
\text { Commercial vehicles }\end{array}$ & $\begin{array}{c}\text { PCA } \\
\text { Passenger cars }\end{array}$ & $\begin{array}{c}\text { APS } \\
\text { Automotive systems }\end{array}$ \\
\hline \multirow[t]{3}{*}{ 1. Launch } & Backgrounds & $\begin{array}{l}\text { Implementation of lean } \\
\text { production }\end{array}$ & $\begin{array}{l}\text { Fostering planning } \\
\text { function in SCM }\end{array}$ & $\begin{array}{l}\text { Implementation of lean } \\
\text { production }\end{array}$ \\
\hline & Motivations & $\begin{array}{l}\text { Further process } \\
\text { improvements } \\
\text { depended on suppliers }\end{array}$ & $\begin{array}{l}\text { Risk of lack of capacity } \\
\text { in critical supply chain }\end{array}$ & $\begin{array}{l}\text { Supply base } \\
\text { consolidation }\end{array}$ \\
\hline & Objective & $\begin{array}{l}\text { To develop key } \\
\text { suppliers' production } \\
\text { capabilities }\end{array}$ & $\begin{array}{l}\text { To ensure order fulfilment } \\
\text { in terms of production } \\
\text { volume and mix }\end{array}$ & $\begin{array}{l}\text { To develop key } \\
\text { suppliers' production } \\
\text { capabilities }\end{array}$ \\
\hline \multirow[t]{3}{*}{ 2. Deployment } & $\begin{array}{l}\text { Driver in the } \\
\text { organisation }\end{array}$ & Production & Purchasing & Logistics \\
\hline & $\begin{array}{l}\text { SC mapping } \\
\text { approach }\end{array}$ & $\begin{array}{l}\text { EVSM with } 1^{\text {st }} \text { tier } \\
\text { supplier }\end{array}$ & $\begin{array}{l}\text { Fine's SC mapping } \\
\text { approach covering } \\
\text { suppliers in tiers } 1 \text { to } 3\end{array}$ & $\begin{array}{l}\text { EVSM with } 1^{\text {st }} \text { tier } \\
\text { supplier }\end{array}$ \\
\hline & $\begin{array}{l}\text { Difficulties } \\
\text { encountered }\end{array}$ & $\begin{array}{l}\text { Commercial } \\
\text { experiences in the past } \\
\text { Misalignment between } \\
\text { internal Production } \\
\text { and Purchasing } \\
\text { policies }\end{array}$ & $\begin{array}{l}\text { Renegotiation of deals } \\
\text { Suppliers facing financial } \\
\text { constraints } \\
\text { Lack of skilled mappers }\end{array}$ & $\begin{array}{l}\text { Commercial experiences } \\
\text { in the past } \\
\text { Resources already } \\
\text { overloaded due to } \\
\text { increasing demand } \\
\text { Inter-firm distance may } \\
\text { constrain interaction }\end{array}$ \\
\hline \multirow[t]{2}{*}{ 3. Outcomes } & $\begin{array}{l}\text { Direct outcomes } \\
\text { in the short-term }\end{array}$ & $\begin{array}{l}\text { Improvements in } \\
\text { quality, lead-time and } \\
\text { cost }\end{array}$ & $\begin{array}{l}\text { Action plans to rise } \\
\text { suppliers capacity }\end{array}$ & $\begin{array}{l}\text { Improvements in } \\
\text { inbound logistics and } \\
\text { productivity gains }\end{array}$ \\
\hline & $\begin{array}{l}\text { Subsequent } \\
\text { developments }\end{array}$ & $\begin{array}{l}\text { Group-wide standard } \\
\text { lean implementation } \\
\text { program adopted } \\
\text { VSM applied in a } \\
\text { rather manneristic way } \\
\text { EVSM only with } 1^{\text {st }} \\
\text { tier supplier } \\
\text { EVSM not supported } \\
\text { by top management }\end{array}$ & $\begin{array}{l}\text { SC mapping seen as } \\
\text { a tool for Supplier } \\
\text { Assessment (cost } \\
\text { breakdown analysis) } \\
\text { Fine's approach not } \\
\text { adopted } \\
\text { VSM in } 1^{\text {st }} \text { tier supplier } \\
\text { plant } \\
\text { EVSM sub-utilised }\end{array}$ & $\begin{array}{l}\text { Simplified SC } \\
\text { development program } \\
\text { expanded to Latin } \\
\text { America } \\
\text { VSM in } 1^{\text {st }} \text { tier supplier } \\
\text { plant } \\
\text { EVSM discontinued }\end{array}$ \\
\hline
\end{tabular}


The set of cases studied, reveal that while at individual level, managers and experts have skilfully learned and applied SC mapping concepts and techniques, have demonstrated their operational viability, and have accomplished objective results, at organisational level, the focal firms have not yet evolved enough to exploit it as a more strategic means. Thus the SC mapping methods are rather seen as analytical tools to be applied in relevant diagnostic projects. Now a major challenge is the incorporation of already developed SC mapping fundamentals in more far-reaching initiatives like dissemination of its systematised application within the group, longterm institutional programs for development of strategic suppliers, and SC redesign.

Table 4 summarises the main aspects of the 3 case studies considered providing a comparative perspective for the analysis of the elements framed in Figure 1. There are differences in the manner the SC mapping was deployed, but with regard to subsequent developments, a similar pattern is found.

The cases reveal that the SC mapping is a complex process that actually requires huge efforts, but still provides invaluable opportunities to strengthen the SC capabilities. However, its adoption as a formal management method by the organisation will depend on clearer understanding of its relevance and potentials. In all cases, the application of a SC mapping method was proposed as a means to deal with a challenging problem involving relevant suppliers by influential and active middle management professionals that had autonomy to deploy it in pioneering initiatives. The application of EVSM or Fine's approach was instrumental in capturing a clear picture of the concerned elements in each SC mapping project and in supporting the mappers to devise effective improvement plans or counter-measures.

The pioneering applications were in general quite successful in achieving the targeted results; nevertheless, the considered initiatives did not contribute to the incorporation of SC mapping practice as a formal management/diagnostic tool. As a matter of fact, this would require the understanding of the relevance of SC mapping for strategic purpose, but in none of the cases top management had close involvement with the SC mapping project. Also, there was no concern to further disseminate the knowledge acquired through each project within the organisation. Despite the existence of diverse SC methods (see section 2), the adherence and actual application of any form of them remain low or null. The devising of an advanced strategy of SC integration at inter-organisational networks level could enhance awareness to these methods, however the focal firms are still rather concentrated in strengthening or rationalising links with key $1^{\text {st }}$ tier suppliers.

\section{FOSTERING THE STRATEGIC NATURE OF THE SUPPLY CHAIN MAPPING}

To foster the exploitation of SC mapping concepts and methods more effectively in organisations like the focal firms considered in the cases studied, more propitious corporate policies and supporting managerial measures should be established. Based on an analysis of the difficulties and obstacles found in the organisation of the focal firms investigated in this study, some potential schemes or mechanisms that may be instrumental in fostering a more strategic exploitation of the SC mapping were organised by the authors, and are pointed out below:

- Influential manager: Creation of value stream manager in a line-command position establishing a strong leadership at the working level to effectively resolve internal disputes about how to implement the improvements opportunities identified in SC mapping projects. The scope of the role and authority of such a leader should be defined considering the existing culture and organisational structure and the positioning of the firm in the SC. Different referential archetypes, like the Product Line Manager (Jones and Womack 2002) and the shusa can be considered.

- Less emphasis on the SC map and its conventions, more gemba spirit: The mapping of a value stream will only bring about reliable information if it is built accurately with carefully gathered data. To paraphrase one analyst at PCA well-versed in EVSM: "It is not unusual that an analyst tackles this activity as deskwork filling in spreadsheets with figures gathered from documents or verbal answers. To get a reliable picture you have to go to the gemba and conduct a thorough on-site assessment". The training of SC mapping experts should not be so focused in the mapping tools and be a more comprehensive process to inculcate a more hands-on attitude and support the development of other assessment skills.

- Integration with supplier assessment system: Nowadays, leading organisations apply structured rating systems based on metrics like tech- 
nology, quality, responsiveness, delivery and cost for supplier assessment, selection and performance measurement with the primary purpose of ensuring contract compliance, reducing risks, and maintaining and improving supplier performance. To also promote a more constructive participation of suppliers in SC mapping initiatives, such systems could also value their attitude to collaboration initiatives.

- Nurturing of long-term partnerships with strategic suppliers: Far reaching programs like selection and development of key suppliers require long-term mutual commitment and structural decisions and these can only be promoted by more stable top management policies.

- Win-win relation: To be successful, a SC mapping initiative must ensure the implementation of the derived action plans. When these are related to suppliers' internal processes they will also expect meaningful benefits. The formalisation of clear win-win relation can avoid situations like fuzziness owing to lack of internal consensus, harsh negotiation struggles or fire-fighting during the deployment of a project.

- First tier suppliers as drivers: Similarly to APS, some leading 1st tier suppliers are developing significant capabilities not only for assessing and developing their own suppliers but also to rearrange the upstream supply base. Automotive OEMs and this type of key suppliers can turn their own SC mapping efforts more efficient by combining their initiatives and exchanging information and experience. This may be a way to develop 1st tier suppliers than can exert a number of more central coordinating roles in the automotive $\mathrm{SC}$, and thus share with automotive OEMs the undertaking of actions seeking the improvement of the industry's overall performance (Hines 1998).

\section{CONCLUSION}

The analysis of the cases studied suggests that SC mapping initiatives had primarily a rather tactical purpose. It is worthy noting that in all cases, the drivers of the initiative were committed to exploit SC mapping in an effective way, thus they struggled to go beyond the capturing of the SC status in maps, and fostered the actual deployment of the macro plans to the level of specific operational countermeasures or solutions for achieving concrete results. However, each initiative was confined to specific areas of the focal firms so to great extent the benefits were constrained within the scope of individual projects.

In the cases studied, each SC mapping project relied on a single mapping method. Such choice may suffice depending on the situation and main purpose. When a more comprehensive mapping is required, different techniques can be complementarily adopted. For instance, applying Fine's (1998) approach of dynamic clockspeed analysis to develop a higher level macro picture of a SC dynamics and technology-related issues, and then applying the VSM method advocated by Womack and Jones (2002) to identify process streamlining opportunities in focal value streams across a chain of firms from a broader perspective.

The SC mapping is not yet a widely diffused practice and its effective application require substantial managerial maturity to promote a more integrative approach for SC planning and management. It also requires organisational competences for assessing production capabilities and carrying out process streamlining actions. With regard to organisational maturity, the strategic vision of SC planning and management should be clearly realised throughout the organisation so that it could be supported more effectively by middle management's efforts in SC mapping.

In other hand, it has been applied by leading firms that found in it a means to support their initiatives to develop the capabilities of their strategic SC partners, and enhance the overall performance of the concerned SCs. However, these application cases consisted in projects that aimed at the solving of local or circumstantial problems involving main suppliers. The focal firms considered have not yet accomplished to institutionalise a more far reaching managerial culture and practices that exploit the use of SC mapping in a more pro-active manner for strategy planning and deployment, or nurturing of advanced SCM practices as suggested in the literature (Fine 1998; Towill, Childerhouse and Disney 2000; Gardner and Cooper 2004). They are still rather treating SC mapping and the maps produced by means of this method as another management tool. This implies concern only with the physical and technical components of a change process in SCM and negligence with the managerial and behavioural components (Lambert and Cooper, 2000). If the latter ones are not readjusted, the effectiveness of the former ones may be seriously hindered.

The insights obtained from this study indicate that the SC mapping approach offers a range of 
benefits and new possibilities to sustain the more advanced patterns of value stream management, but further studies should be developed to facilitate its wider adoption as a method with strategic implications. A major challenge seems to be the need to overcome obstacles like conflicting interests, disconnects between strategic ends and tactical means, scepticism, and lack of inclination to collaborate not only at the suppliers' side, but inside the own organisation as well.

\section{REFERENCES}

Bessant, J.; Kaplinsky, R. and Lamming, R Putting supply chain learning into practice, International Journal of Operations \& Production Management, 2003, 23(2), 167-184.

Brazilian Association of Autoparts Manufacturers, Brazilian Autoparts Industry Performance 2007, 2007 (Sindipeças: São Paulo, SP). Available online at:

http://www.sindipecas.org.br/ (accessed 17 January 2008).

Childerhouse, P. and Towill, D.R. Simplified material flows holds the key to supply chain integration, Omega, 2003, 31, 17-27.

Drickhamer, D. See the big picture: extended value stream mapping offers a practical approach to developing customer and supplier partnerships, Industry Week, March 2003, 252, p.57.

Favaro, C. and Lima, P.C., Extended value stream mapping applied in automobile industry to design a lean supply chain, in Proceedings of $18^{\text {th }}$ Intl. Congress of Mechanical Engineering, 2005, Ouro Preto, MG, 7p.

Fawcett, S.E. and Magnan, G.M. The rethoric and reality of supply chain integration, International Journal of Physical Distribution \& Logistics Management, 2002, 32(5), pp.339-361.

Fine, C., Clockspeed: winning industry control in the age of temporary advantage, 1998 (Perseus Books: Reading, MA).

Gardner J.T. and Cooper M.C., Strategic supply chain mapping approaches, Journal of Business Logistics, 2003, 24(2), 37-64.

Harland, C.M.; Lamming, R.C. and Cousins, P.D. Developing the concept of supply strategy. International Journal of Operations \& Production Management, 1999, 19(7), 650-673.

Harper, J. Implementing lean material management in an extended value stream. Massachusetts Institute of Technology, Leaders for Manufacturing Program, master dissertation, 2007, Cambridge, MA, 101p.

Hines, P. Creating world class suppliers: Unlocking mutual competitive advantage,1994 (Pearson Education: London, UK).

Hine, P. Benchmarking Toyota's supply chain: Japan vs U.K. Long Range Planning, 1998, 31(6), 911-918.

Hines, P. and Rich, N., The seven value stream mapping tools, International Journal of Operations \& Production Management, 1997, 17(1), 46-64.
Hines, P. and Rich, N., Outsourcing competitive advantage: the use of supplier associations. International Journal of Physical Distribution \& Logistics Management, 1998, 28(7), 524-546.

Hines, P.; Rich, N. and Hittmeyer, M. Competing against ignorance: advantage through knowledge. International Journal of Physical Distribution \& Logistics Management, 1998, 28(1), 18-43.

Hines, P.; Rich, N.; Bicheno, J.; Brunt, D.; Taylor, D.; Butterworth, C.; Sullivan, J. Value stream management, The International Journal of Logistics Management, 1998, 9(1), 25-42.

Hines, P.; Lamming, R.; Jones, D.; Cousins, P. and Rich, N. Value stream management: strategy and excellence in the supply chain, 2000 (Pearson Education, London, UK).

Hoyt, J. and Huq, F., From arms-length to collaborative relationships in the supply chain: an evolutionary process. International Journal of Physical Distribution \& Logistics Management, 2000, 30(9), 750-764.

International Organization of Motor Vehicle Manufacturers/ OICA. World motor vehicle production by country 20082009. Available online at:

http://oica.net/category/production-statistics/ (accessed June 2010)

Jones, D.; Hines, P. and Nick, R. Lean logistics International Journal of Physical Distribution \& Logistics Management, 1997, 27(3/4), 153-173.

Jones, D. and Womack, J.P. Seeing the whole: mapping the extended value stream, 2002 (Lean Enterprise Institute: US).

Lambert, D.M.; Cooper, M.C. and Pagh, J.D. Supply chain management: implementation issues and research opportunities, International Journal of Logistics Management, 1998, 9(2), 1-19.

Lambert, D.M.; Cooper, M.C. Issues in supply chain management, Industrial Marketing Management, 2000, 29, 65-83.

Miyake, D.I. and Nakano, D. Implementation of corporate production systems in the Brazilian auto industry: managing knowledge through practice. International Journal of Automotive Technology and Management, 2007, 7(2/3), 153-167.

Naim, M.M.; Childerhouse, P.; Disney, S.M. and Towill, D.R. A supply chain diagnostic methodology: determining the vector of change, Computers \& Industrial Engineering, 2002, 43, 135-157.

Roldan, F., Gestão da cadeia de suprimentos na indústria automobilística brasileira - A coordenação das informações de volume e de mix de produção. 2005, Master's dissertation, Escola Politécnica da USP, São Paulo.

Rother, M. and Shook, J. Learning to see: value stream mapping to add value and eliminate muda, 1998 (Lean Enterprise Institute: Brookline, MA).

Sako, M. Supplier development at Honda, Nissan and Toyota: comparative case studies of organizational capability enhancement. Industrial and Corporate Change, 2004, 13(2), 281-308. 
Stake, R.E. Multiple case study analysis, 2005 (The Guilford Press: New York, NY).

Supply Chain Council, Supply-chain operations reference-model: SCOR version 8.0 overview, 2006 (Supply Chain Council: Pittsburgh, PA) http://www.supply-chain.com/

Taylor, D. and Brunt, D. Manufacturing operations and supply chain management: The lean approach, 2001 (Thompson Learning, London, UK).

Towill, D.R., Childerhouse, P. and Disney, S.M., Speeding up progress curve towards effective supply chain management. Supply Chain Management: an International Journal, 2000, 5(3), 122-130.
Yin, R.K. Case study research: design and methods, Applied Social Research Methods Series, v.5, $2^{\text {nd }}$ ed., 1994 (Sage Publications: Thousand Oaks, CA).

\section{ACKNOWLEDGEMENTS}

The first author is grateful to The State of São Paulo Research Foundation (FAPESP) and to The National Council for Scientific and Technological Development $(\mathrm{CNPq})$ for the support received under Grant No. 07/04280-7 and Process No. 307387/2007-0, respectively.

\section{AUTHORS' BIOGRAPHY}

Dario Ikuo Miyake received his Master's Degree in Production Engineering from University of São Paulo and Ph.D. in Industrial Engineering and Management from the Tokyo Institute of Technology. He was a postDoctoral Visitor of the Center for International Research on Japanese Economy of the University of Tokyo. Currently he is an Assistant Professor at the Department of Production Engineering, Escola Politécnica, University of São Paulo.

Alvair Silveira Torres Junior is Assistant Professor at the Department of Business Management at the School of Economics, Business and Accounting, in the University of São Paulo (FEA-USP). He received his Ph.D. in Organizational Communication from Metodista University of São Paulo and his Master's Degree in Business Management from Catholic University of São Paulo (PUC-SP). After over 15 years assisted companies in implementing lean production, he is currently dedicated to the research of lean management in its relations with technology management, decision analysis and operational strategy.

Cleber Favaro is a Ph.D. student of Mechanical Engineering at State University of Campinas (Unicamp). He holds a M.Sc. and B.Sc. degrees in Mechanical Engineering from Unicamp. Currently he is working at ZF do Brasil where is responsible for coordinating the implementation of lean manufacturing concept and six sigma methodology in South America for Commercial Vehicle and Off-Road Driveline Technology Divisions. 